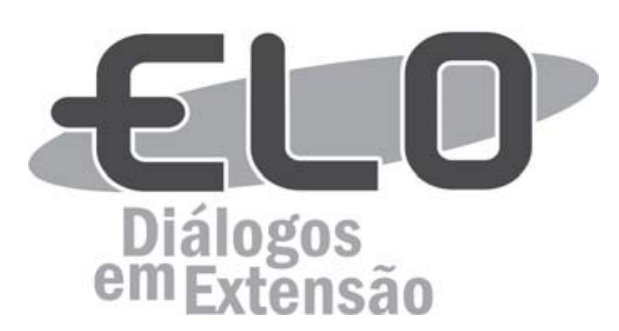

\title{
Construindo saberes sobre desenvolvimento rural sustentável e agroecologia: uma experiência com extensão universitária
}

André Wagner Barata Silva', Viviane Santos Pereira², Luiz Antônio Augusto Gomes ${ }^{3,4}$

Resumo: Este artigo tem como objetivo compartilhar uma experiência com extensão universitária sobre a construção de saberes, para a promoção do desenvolvimento rural sustentável, a partir da agroecologia no município São Thomé das Letras - MG. Foram realizadas dez reuniões e doze atividades com a comunidade em vinte meses. Inicialmente foi realizado um diagnóstico participativo, e todas as ações foram construídas de forma coletiva, considerando-se as demandas da comunidade. Observaram-se, no decorrer do projeto, algumas limitações, principalmente, relacionadas à falta de financiamento e à participação às reuniões. Como potencialidades, ressaltam-se as diversas possibilidades dos atores sociais envolvidos em aprender, dialogar e ensinar sobre o desenvolvimento rural sustentável e agroecologia. Essa experiência foi marcada pelo diálogo e troca de saberes, ao buscar superar a ideia de transmissão de conhecimentos da universidade para a sociedade.

Palavras-chave: Extensão universitária. Desenvolvimento rural sustentável. Agroecologia.

Área Temática: Agroecologia. Meio Ambiente.

\section{Building knowledge on sustainable rural development and agroecology: an experience with university extension}

\begin{abstract}
This article aims to share an experience with university extension on the construction of knowledge to promote sustainable rural development from agroecology in the municipality of the São Thome das Letras - MG. Ten meetings and twelve community activities were held in twenty months. Initially a participatory diagnosis was carried out and all the actions were constructed collectively considering the demands of the community. During the course of the project, there were some limitations mainly related to lack of funding and participation in meetings. As potentialities, the various possibilities of the social actors involved in learning, discussing and teaching about sustainable rural development and agroecology are highlighted. This experience was marked by dialogue and exchange of knowledge, seeking to overcome the idea of transmitting knowledge from university to society.
\end{abstract}

Keywords: University Extension. Sustainable rural development. Agroecology.

\section{Construyendo conocimientos sobre desarrollo rural sostenible y agroecologia: una experiencia con extensión universitaria}

Resumen: Este artículo tiene como objetivo compartir una experiencia con extensión universitaria sobre construcción de saberes para promover el desarrollo rural sostenible a partir de la agroecología en el municipio São Thomé das Letras - MG. Se realizaron diez reuniones y doce actividades con la

\footnotetext{
${ }^{1}$ Doutorando no Programa Pós-Graduação em Agronomia/Fitotecnia da Universidade Federal de Lavras.

${ }^{2}$ Professora da Universidade Federal de Lavras. Coordenadora do projeto de extensão. End.: Departamento de Administração e Economia da Universidade Federal de Lavras. Caixa postal 37. Lavras/MG. CEP 37200-000. Tel.(35)3829-1459. E-mail: vivianepereira@ufla.br

${ }^{3}$ Professor no Programa Pós-Graduação em Agronomia/Fitotecnia da Universidade Federal de Lavras.

${ }^{4}$ Professor na Universidade Federal de Uberlândia - Campus Patos de Minas/MG.
} 
comunidad en veinte meses. Inicialmente se realizó un diagnóstico participativo y todas las acciones fueron construidas de forma colectiva considerando las demandas de la comunidad. En el transcurso del proyecto se observaron algunas limitaciones principalmente relacionadas con la falta de financiamiento y la participación en las reuniones. Como potencialidades, se resaltan las diversas posibilidades de los actores sociales involucrados de aprender, dialogar y enseñar sobre desarrollo rural sostenible y agroecología. Esta experiencia fue marcada por el diálogo y el intercambio de saberes, buscando superar la idea de transmisión de conocimientos de la universidad a la sociedad.

Palabras clave: Extensión universitaria. Desarrollo rural sostenible. Agroecología.

\section{Introdução}

Em decorrência do atual modelo econômico, causador de desequilíbrios ambientais, a sociedade vem passando por mudanças substanciais, pois o atual modelo de crescimento econômico tem gerado enormes desequilíbrios ao meio ambiente. Os avanços obtidos pela sociedade atual são tão visíveis quanto os prejuízos que os modelos convencionais de desenvolvimento rural e urbano provocaram.

A noção de desenvolvimento, historicamente relacionada ao crescimento econômico, vai além do domínio da economia, à medida que incorpora aspectos sociais, ambientais, culturais e políticos, sustentando-se em novas visões pela busca de soluções para enfrentar os problemas socioambientais. Isso representa uma mudança, no paradigma dominante sobre os caminhos para o desenvolvimento, reconhecendo a incompletude e a insuficiência dos modelos econômicos e sociais que têm servido de apoio e orientação aos processos de desenvolvimento.

Nota-se que as estratégias convencionais de desenvolvimento são insuficientes para minimizar as crescentes condições de desigualdade, exclusão social e degradação do meio ambiente. Estudos e contribuições, decorrentes das novas visões sobre o processo de desenvolvimento, passaram a incorporar, de forma cada vez mais evidente, a problemática da sustentabilidade (CAPORAL E COSTABEBER, 2004).

A procura por uma sustentabilidade, no desenvolvimento rural, implica reconhecer a existência de saberes construídos, mediante uma lógica indutiva, que vai sendo estabelecida na história dos grupos sociais. Para Moreira e Carmo (2004), a sustentabilidade e a estratégia de desenvolvimento rural devem ser definidas a partir da participação e da identidade etnoecossistêmica de cada localidade a ser considerada.

Nesse sentido, a integração de diferentes conhecimentos científicos, em diálogo com outras formas de conhecimento, tem ganhado cada vez mais espaço, para a construção de um processo de desenvolvimento rural sustentável, embasando-se na agroecologia que tem oferecido princípios, bases técnicas e metodológicas que visam apoiar essa transição. Tendo o entendimento da agroecologia, enquanto campo de estudos de caráter multidisciplinar, tomaram-se, como base conceitual, os trabalhos de Caporal e Costabeber (2004), Altieri (2002), Casado, Molina e Guzmán (2000) e Gliesman (2000).

Casado, Molina e Guzmán (2000) afirmam que a agroecologia é um enfoque científico que reúne vários campos de conhecimento, incorporando reflexões teóricas e avanços científicos de distintas disciplinas. Conforme Gliessman (2000), a agroecologia é entendida como aplicação de princípios e conceitos no manejo e desenho de agroecossistemas sustentáveis. Já Altieri (2002) declara que a agroecologia é uma ciência que fornece os princípios ecológicos básicos, para estudar, desenhar e manejar agroecossistemas produtivos, que conservem recursos naturais, que sejam culturalmente apropriados, socialmente justos e economicamente viáveis.

Segundo Caporal e Costabeber (2004), a intenção da agroecologia vai além de aspectos agronômicos de produção, incorporando dimensões mais abrangentes e complexas da produção agrícola. Desta forma, a agroecologia orienta, também, processos de desenvolvimento rural sustentável. Nessa perspectiva, para ser sustentável, o processo de desenvolvimento rural precisa considerar as diferentes dimensões da sustentabilidade (social, econômica, ambiental, cultural, política e ética) em uma perspectiva que não abandona a solidariedade intra e intergeracional (COSTABEBER E CAPORAL, 2003).

Assim, de acordo com Caporal et. al (2009), a proposta de desenvolvimento rural sustentável necessita de esforços à identificação e à construção de saberes ecológicos, agronômicos, econômicos e sociais que permitam, de forma participativa, desenvolver processos toleráveis de exploração da natureza e compatíveis com as exigências de reprodução social das famílias. 
[...] a agroecologia se nutre de outros campos de conhecimento e de outras disciplinas científicas, assim como de saberes, conhecimentos e experiências dos próprios agricultores, o que permite o estabelecimento de marcos conceituais, metodológicos e estratégicos [...] (CAPORAL e COSTABEBER, 2004 p. 108).

Sob esta ótica, a integração de diferentes conhecimentos científicos, em diálogo com o conhecimento tradicional e saber local, tem ganhado cada vez mais espaço, para a construção de um processo de desenvolvimento rural sustentável, sendo a interação entre a universidade e a sociedade, por meio da extensão universitária, um importante caminho para alcançar esse objetivo.

De acordo com o FORPROEX (2012), ao longo do tempo, a Extensão Universitária tornou-se instrumento de inter-relação da Universidade com a sociedade, de oxigenação da própria Universidade, de democratização do conhecimento acadêmico, assim como de (re) produção desse conhecimento por meio da troca de saberes com as comunidades. A Extensão Universitária denota uma postura da Universidade, na sociedade em que se insere, entendida como um processo interdisciplinar, educativo, cultural, científico e político, por meio do qual se promove uma interação transformadora. Para que essa interação seja dialógica, faz-se necessária a aplicação de metodologias que estimulem a participação e a democratização do conhecimento, destacando a contribuição de atores não universitários em sua produção e multiplicação.

Por isso, a extensão deve ser um processo educativo que considera a comunicação, a cultura, a visão de mundo e a realidade local, a fim de problematizar questões, ao estabelecer diálogos entre o conhecimento científico e outras formas de conhecimento em qualquer temática. Ressalta-se, nesse cenário, um dos objetivos da Política Nacional de Extensão Universitária que é o de estimular a educação ambiental e o desenvolvimento sustentável como componentes da atividade extensionista (FORPROEX, 2012).

Nesse contexto, torna-se relevante o desenvolvimento de ações de extensão universitária, alinhado a uma perspectiva de extensão, que busca contribuir para a promoção do desenvolvimento rural sustentável, adotando uma abordagem sistêmica e multidisciplinar, mediante a utilização de métodos participativos. Diante do exposto, este artigo apresenta um projeto de extensão universitária sobre desenvolvimento rural sustentável.

\section{Objetivos}

O projeto de extensão, aqui apresentado, teve como objetivo estimular a construção de saberes, para a promoção do desenvolvimento rural sustentável, a partir da agroecologia no município de São Thomé das Letras/MG, por meio da promoção de espaços de diálogo e aprendizagem.

\section{Metodologia}

Neste projeto, optou-se por realizar um processo de "intervenção na concepção participativa", conforme proposto por France (2005 p. 113), visando a uma construção compartilhada de conhecimentos entre pessoas com formações distintas, pontuando os princípios gnosiológicos da concepção construtivista de aprendizagem - ato de conhecer como um processo em construção. Assim, não ocorre apenas a assimilação de novos conhecimentos, mas a transformação dos conhecimentos já incorporados pela prática. Nesse processo, há participação do grupo atingido "desde os atos de problematização até os de decisão" (FRANCE, 2005).

O Diagnóstico Rural Participativo (DRP), também, foi utilizado como ferramenta metodológica. De acordo com Verdejo (2006), o DRP é um conjunto de técnicas e ferramentas que permite que as comunidades façam o seu próprio diagnóstico e, a partir daí, comecem a autogerenciar o seu planejamento e desenvolvimento. Dessa maneira, os participantes podem compartilhar experiências e analisar os seus conhecimentos, a fim de melhorar as suas habilidades de planejamento e ação.

Em sua realização, o projeto de extensão intitulado "Construção de saberes para a promoção do desenvolvimento rural sustentável pela agroecologia em São Thomé das Letras" estava vinculado ao Departamento de Administração e Economia (DAE) da Universidade Federal de Lavras (UFLA) e foi desenvolvido no município de São Thomé das Letras - MG. A Sociedade Brasileira de Eubiose da referida cidade (SBE-STL), ainda, foi parceira na realização do projeto. 
A equipe do projeto foi composta, incialmente, por uma professora da UFLA, também coordenadora do projeto e por um doutorando do Programa de Pós-Graduação em Fitotecnia da universidade. Posteriormente, a equipe teve a participação de dois estudantes de graduação (Agronomia e Administração).

As ações se deram entre abril de 2017 e dezembro 2018 e ocorreram, sobretudo, por meio de reuniões e atividades.

Nas reuniões, as pautas eram construídas coletivamente. Eram definidas e organizadas as atividades, que seriam realizadas, de acordo com o tema e formato, tais como: oficinas, visitas, palestras, cursos, entre outros. Ao longo desses vinte meses, foram realizadas dez reuniões e doze atividades teóricas e práticas com a comunidade. Os participantes do projeto totalizaram vinte e cinco moradores da zona rural e urbana do município. As reuniões tiveram duração de quatro horas e houve, em média, a participação de nove pessoas. A comunicação entre os participantes e a equipe do projeto ocorria, principalmente, por meio das redes sociais em que eram socializadas informações sobre as temáticas de interesse, sínteses das reuniões, definição de pautas, avisos e articulação entre os participantes. Cabe ressaltar que esse projeto não obteve financiamento, sendo as despesas com viagem, materiais de escritório e alimentação custeadas pelos membros da equipe.

\section{Resultados e discussão}

A idealização deste projeto surgiu, a partir do convívio de um dos membros da equipe (doutorando) com a realidade do município, ao longo dos últimos dez anos. Após sua participação em movimentos sociais, como membro do Conselho Municipal de Defesa e Conservação do Meio Ambiente (CODEMA) e representante do município no Comitê da Bacia Hidrográfica do Rio Verde, percebeu-se, no que diz respeito a inúmeros conflitos socioambientais no município, o interesse e demanda da comunidade, em aprofundar seus conhecimentos sobre a temática do desenvolvimento rural sustentável, aproximando-se de sua realidade. A partir de abril de 2017, foram realizadas reuniões entre a equipe do projeto e a organização parceira (SBE/STL), a fim de iniciar o contato e o convite à comunidade do município. A organização parceira disponibilizou seu espaço físico, para a realização das reuniões e atividades. Após elaborar uma carta-convite - (explicando o propósito do projeto de extensão) - foi divulgada aos interessados, por meio das redes sociais da comunidade, para as organizações locais, além de abordagens pessoais com moradores da zona rural.

A primeira reunião foi realizada, no início de agosto e dela participaram onze moradores tanto da zona rural como da zona urbana do município. Inicialmente houve a apresentação dos presentes, seguida de exposição e discussão do projeto e intervalo para café com prosa. Logo depois do intervalo, foi realizado um diagnóstico participativo, sendo problematizada a percepção da realidade do município pelos participantes e levantamento de demandas com temas e atividades de interesse.

Dentre as principais demandas, ressaltam-se, por ordem de importância, o interesse por espaços teóricos e práticos sobre a conservação de recursos hídricos; alternativas para emprego e renda, via fortalecimento da economia solidária; capacitações em agroecologia, alimentação e aproveitamento dos alimentos; produção orgânica e identificação dos produtores rurais do município.

Todos os temas apresentados, nas demandas dos participantes, têm relação com a agroecologia e podem fortalecer processos para a promoção do desenvolvimento rural sustentável.

Como encaminhamentos dessa primeira reunião, definiu-se que a equipe do projeto ficaria responsável por contatar docentes e profissionais que pudessem contribuir, compartilhando saberes, em espaços dialógicos, relacionados às temáticas de interesse do grupo. Além disso, foi estipulado que os próprios participantes do projeto também iriam compartilhar seus saberes. Assim, as pautas das reuniões foram construídas, coletivamente, por meio das demandas e encaminhamentos de reuniões anteriores.

As reuniões, geralmente, ocorriam no primeiro ou terceiro sábado do mês, em função das atividades desenvolvidas pela organização parceira Sociedade Brasileira da Eubiose. Ao início das reuniões, costumava-se fazer um breve resgate da pauta anterior e, logo depois, dos itens seguintes. A coordenadora do projeto conduzia a reunião, fazendo papel de mediadora, e o doutorando o papel de cofacilitador que auxiliava a mediadora, buscando agilizar e dinamizar o trabalho, favorecendo um ambiente de aprendizagem.

Ambos se responsabilizaram por organizar o tempo de fala de cada participante, a fim de se evitar centralizações; controlar o tempo das discussões sobre cada ponto de pauta, para que se 
alcançassem os objetivos propostos em cada reunião; fazer os relatórios de cada encontro; estimular o debate e a reflexão; fazer sínteses sobre as tomadas de decisão e encaminhamentos, buscando alinhar, dar maior clareza e resgatar os aspectos centrais ao longo das reuniões.

Em quatro reuniões, os estudantes de graduação puderam participar e, também, colaboraram por meio de mediação e realização de relatórios.

Durante as reuniões, eram definidas as temáticas, organizadas as atividades que seriam realizadas (data e formato, por exemplo), assim como as responsabilidades de cada participante. Após cada reunião, era disponibilizada uma síntese contendo data, participantes presentes, os pontos de pauta com respectivas discussões e decisões, informes e encaminhamentos.

Geralmente às reuniões compareciam nove pessoas, em média, cinco mais assíduas e as demais menos frequentes. Algumas tiveram dificuldades, para frequentar todas as reuniões, no entanto acompanhavam o grupo e participavam dele, mais ativamente, pelas redes sociais. Essas dificuldades tornaram-se assuntos de duas das reuniões e estavam relacionadas a diversos fatores tais como: impossibilidade de conciliar o dia da reunião com o trabalho, pois as principais fontes de renda do município advêm do turismo e da mineração; tempo de duração das reuniões, pois tomavam a tarde toda; e logística, visto que a maioria residia na zona rural e não conseguia carona, ou mesmo pelas condições das estradas e do tempo.

Durante o desenvolvimento do projeto, foram realizadas duas avaliações, (em dezembro de 2017 e dezembro de 2018), que tiveram como objetivo analisar as reuniões e as atividades desenvolvidas, potencializando os aspectos positivos, compreender as dificuldades vivenciadas e pensar estratégias e sugestões para aperfeiçoar os processos.

Apesar de as dificuldades encontradas, uma parcela do grupo se manteve assídua, ao longo do tempo, participando das reuniões e desenvolvendo uma série de atividades que foram avaliadas pelos participantes como muito enriquecedoras. Destacam-se o empenho e a participação do grupo, o qual se manteve frequente às ações do projeto, seja na definição das temáticas, data e local, formato das atividades, assim como na divulgação e articulação com a comunidade.

Segue uma breve descrição de cada uma das doze atividades desenvolvidas ao longo dos vinte meses do projeto.

A primeira atividade organizada foi com a participação de quatro pessoas do projeto, na etapa do Circuito Sul Mineiro de Agroecologia de 2018, que ocorreu na cidade de Maria da Fé/MG.

Esse foi um evento organizado pela "Orgânicos Sul de Minas" com duração de um dia. Nesse evento, os membros da Associação de Produtores de Agricultura Natural de Maria da Fé/APANFÉ receberam outros produtores e demais participantes, a fim de problematizar, compartilhar, realizar capacitações sobre produção orgânica e, também, trocar sementes crioulas em uma das propriedades dos membros da APANFÉ. Foram abordadas as técnicas de produção de adubo orgânico bokashi e de microorganismos eficientes (E.M). Os quatro participantes do projeto compartilharam essa experiência com os demais, na reunião seguinte, de forma oral, por meio de resumo escrito e fotos, salientando as técnicas e as aprendizagens, bem como a satisfação em participar de espaços de trocas de experiências.

A segunda atividade foi uma palestra sobre desenvolvimento rural sustentável e Agroecologia conduzida pelo doutorando membro da equipe do projeto. A palestra, que foi expositiva e dialogada, teve duração de duas horas e problematizou os modelos convencionais de desenvolvimento e como essa crise socioambiental cria possibilidades, para maiores questionamentos sobre os princípios, valores e técnicas, que orientam o desenvolvimento rural. Foram apresentados dados sobre a realidade rural brasileira, com o objetivo de estimular a reflexão e o debate sobre como a concepção de desenvolvimento pode contribuir, para aumentar ou diminuir as desigualdades sociais, sobrevivência e manutenção da população no campo, assim como a agroecologia, para a promoção de um desenvolvimento rural sustentável.

A terceira atividade organizada foi uma palestra expositiva dialogada sobre preservação de recursos hídricos, com duração de duas horas, à qual compareceram 15 pessoas. A roda foi conduzida pelo professor de hidrologia, Marcelo Ribeiro Viola, do Departamento de Engenharia da UFLA, que abordou a importância da conservação dos recursos hídricos, a legislação sobre o tema e conversou sobre o projeto de pesquisa que estava sendo desenvolvido sobre o monitoramento hidrológico do Ribeirão Canta Galo, principal afluente da Área de Proteção Ambiental (APA) - São Thomé, no qual estão inseridas as cachoeiras que são os principais pontos turísticos do município. Além disso, os interessados foram convidados a participar da atividade prática de coleta de dados para o monitoramento do ribeirão. 
A quarta atividade foi sobre métodos de monitoramento hidrológico, também, conduzida pelo professor de hidrologia do Departamento de Engenharia e por um técnico da UFLA. Essa atividade teve duração de dois dias e a participação de três membros do projeto de extensão que acompanharam as atividades de pesquisa do professor. Tais atividades consistiram na coleta de dados referentes à velocidade de infiltração da água no solo e à instalação de sensores e régua de nível no ribeirão, sendo assim, foram instalados pluviômetros e estações meteorológicas na microbacia do Ribeirão Canta Galo.

Ressalta-se a importância da temática da água para os participantes. Ao longo do tempo, eles perceberam que o curso do ribeirão, apesar de essencial para o abastecimento do município e para a promoção de um desenvolvimento rural sustentável, tem se tornado cada vez mais escasso e poluído. O município tem o turismo como importante segmento, para a geração de ocupação e renda, sendo baseado em recursos hídricos como as cachoeiras e as belezas paisagísticas naturais. Nesse contexto, surgem conflitos socioambientais relacionados à sua degradação, em decorrência do turismo em massa e do crescimento desordenado das populações rural e urbana que trazem muitos desafios em torno do tema da água no município. Existe, inclusive, um grupo informal no município, denominado Movimento Todos pela Água, que tem atuado, nos últimos anos, em defesa das águas do município e alguns participantes do projeto de extensão são integrantes desse movimento.

A quinta atividade organizada foi uma oficina sobre economia solidária e alternativa para a geração de renda. Ela foi conduzida por uma economista e mestranda do Programa de Pós-Graduação em Desenvolvimento Sustentável e Extensão da UFLA (PPGDE). A oficina teve início com uma exposição dialogada pelos sete participantes sobre o conceito e os princípios da economia solidária. Foram apresentadas e discutidas algumas iniciativas em Minas Gerais e em todo Brasil. Posteriormente ocorreu uma discussão sobre alternativas de geração de renda, para o município, em que se destacou o fortalecimento da produção orgânica e o acesso a políticas públicas como o Programa Nacional de Alimentação Escolar (PNAE). Percebeu-se que a proposta de uma economia solidária estava alinhada ao pensamento dos participantes, à medida que o espaço de discussão estimulava trocas, socializações e propostas alternativas tanto no que se refere à permuta de materiais e produtos, quanto a informações e conhecimentos. Essa oficina instigou os participantes do projeto a utilizarem mais os espaços de encontro e as redes sociais, para compartilhar informações, livros, mudas, sementes, dentre outras.

A sexta atividade ocorreu, por meio de uma palestra sobre gestão de bacias hidrográficas e conservação de estradas rurais, conduzida por outro professor do Departamento de Engenharia da UFLA, Gilberto Coelho. A palestra teve duração de três horas, na qual se discutiram a importância das bacias hidrográficas e o papel dos comitês de bacia, assim como algumas demandas relacionadas ao impacto ambiental sobre o Ribeirão Canta Galo - decorrentes da retirada de água para o abastecimento da zona urbana do município. Quanto à conservação das estradas, foram apresentadas algumas fotos de estradas rurais do município e, além disso, foi articulada junto ao professor a possibilidade de ministrar um curso teórico e prático sobre a conservação de estradas rurais para os profissionais da prefeitura. Os participantes deram ideias de locais, para sua realização e comunicaram à prefeitura essa probalidade.

A sétima atividade foi uma oficina sobre (re)aproveitamento integral de alimentos e ocorreu em casa de uma das participantes do projeto com a presença de 15 pessoas. Esse evento teve duração de 5 horas e foi conduzido por dois participantes do projeto que prepararam um espaço teórico e prático sobre esse tema, seguido de uma confraternização. Na atividade prática, foram preparadas quatro receitas (caskalouca de banana, arroz com talos, suco verde e salada de frutas) que foram oferecidas como refeição ao grupo durante a confraternização. A receita de caskalouca, que utiliza a casca da banana e o uso dos talos no arroz, chamou muito a atenção quanto às possibilidades de aproveitamento integral de alimentos, além de outras sugestões culinárias, como conservação de alimentos, compartilhadas entre todos.

A oitava e nona atividade surgiu, a partir da organização dos participantes, para viabilizar dois cursos gratuitos ofertados pelo Senar/MG, ambos com duração 20 horas (curso de recuperação de nascentes e de recuperação de áreas degradadas) que ocorreram nas propriedades rurais dos participantes do projeto. Uma vez que a temática da água era de grande interesse dos partícipes, tema central ou transversal de outras atividades e, diante da disponibilidade da realização dos cursos, o grupo se mobilizou estimulando moradores de seus bairros e demais interessados. Verificou-se que ter disponibilidade de tempo, para se dedicar a um curso de 20 horas, é um desafio, pois é necessário priorizar essa escolha em detrimento de outras atividades que fazem parte da rotina, compromissos e necessidades dos moradores. 
O curso de recuperação de nascentes reuniu 15 pessoas, às quais foi aplicada a técnica de recuperação de nascentes, na propriedade de um membro do projeto. Como resultado, providenciouse o aumento da vazão da nascente e a articulação de um mutirão solidário, para a recuperação de nascentes em outras propriedades, visando contribuir com a melhoria do meio ambiente do município e, também, praticar, consolidar e compartilhar a técnica aprendida. O curso de recuperação de áreas degradadas ocorreu em propriedade de outro participante do projeto e estiveram presentes 16 pessoas, sendo recuperada uma área degradada, apresentando início de voçoroca, provocada por processos erosivos causados pela água.

A décima atividade se referiu a uma oficina sobre Plano de Manejo de APA da qual participaram 20 pessoas e teve duração de quatro horas. Foi conduzida pelo professor substituto do Instituto Federal do Sudoeste de Minas, Vinícius do Couto Carvalho, que abordou a temática, capacitando o conceito, papel, aspectos legais e importância de um plano de manejo, para uma Unidade de Conservação, como, por exemplo, uma APA, assunto de grande interesse dos participantes do projeto de extensão. Destacou-se a importância da APA - São Thomé, para o município e sua relação quanto à conservação dos recursos hídricos, paisagísticos e turísticos, demostrando a necessidade do envolvimento da comunidade nesse processo.

A décima primeira e a décima segunda atividades fizeram parte da semana do meio ambiente do município de São Thomé, uma vez que os participantes do projeto foram convidados a colaborar com o evento. Realizaram-se duas atividades com estudantes da escola estadual do município, quais sejam, uma oficina sobre aproveitamento integral de alimentos e oito palestras sobre o controle biológico de insetos-praga em sistemas orgânicos.

A oficina sobre aproveitamento integral dos alimentos foi conduzida por três participantes do projeto (uma nutricionista, um proprietário de restaurante e um analista de mídias sociais) e teve como objetivo difundir os conhecimentos teórico-práticos a respeito desse tema com as merendeiras da escola que também ajudaram a preparar a receita da caskalouca de banana, para ser servida com pão, no lanche (merenda), ao turno da tarde, para cem estudantes do ensino fundamental. Essa oficina foi compartilhada, na reunião seguinte, como sendo algo muito gratificante. Segundo relatos, o fato de a caskalouca se parecer muito com uma carne causou muita surpresa e interesse por parte dos estudantes e dos colaboradores da escola.

Nessa mesma semana e escola, ocorreram palestras sobre controle biológico de insetos-praga em sistemas orgânicos, sendo repetidas oito vezes, ao longo do turno da manhã e tarde, para estudantes do ensino fundamental e médio da escola (200 estudantes). A oficina sobre controle biológico foi conduzida pelo professor Luís Cláudio Paterno Silveira do Departamento de Entomologia da UFLA; um estudante de doutorado em Entomologia; um doutorando em Fitotecnia, também membro da equipe e, ainda, contou com apoio de três participantes do projeto de extensão. O objetivo da oficina foi despertar nas crianças e adolescentes o entendimento sobre a importância dos insetos ao meio ambiente. Para isso, foi-lhes apresentada uma palestra rápida, bastante ilustrativa e, em seguida, os alunos puderam ver a diversidade das ordens de insetos, por meio de coleções entomológicas, assim como puderam manipular insetos vivos criados no Departamento de Entomologia. Destacaram-se a curiosidade e o interesse dos estudantes no assunto, como também a satisfação daqueles que conduziram ou colaboraram para que essa atividade acontecesse.

Após a realização de dez reuniões e doze atividades com a comunidade, observaram-se dificuldades e potencialidades. Quanto às dificuldades, ressaltam-se as limitações pela falta de financiamento, para cobrir despesas com materiais de escritório, viagens e alimentação, mas, por outro lado, sempre houve empenho em encontrar soluções para minimizá-las, tais como organização (por parte da equipe e dos participantes do projeto) de lanches, hospedagem e alimentação solidária ofertada aos profissionais convidados, entre outros. Um aspecto limitante se referiu à dificuldade de estímulo à participação de pessoas, nas reuniões de elaboração, estruturação e execução das atividades. Entretanto houve grande comprometimento e dedicação por parte daqueles se que se prontificaram a participar, com frequência, tanto das reuniões como das atividades.

Além dessa potencialidade, notou-se a satisfação dos participantes diante da possibilidade de se capacitar, aprender, dialogar e ensinar sobre temáticas que são relevantes à sua realidade, sendo demandadas e entendidas como formidáveis a eles e que estão alinhadas com a proposta de promoção do desenvolvimento rural sustentável.

Essa nova perspectiva de desenvolvimento, segundo Costabeber e Caporal (2003), em sua formulação mais ampla, significa a realização de potencialidades sociais, culturais e econômicas de 
uma sociedade, em sintonia com o seu entorno ambiental e com seus valores políticos e éticos. Esses autores defendem o desenvolvimento rural sustentável como um processo gradual de mudança que encerra, em sua construção e trajetória, a consolidação de processos educativos e participativos que envolvem as populações, conformando uma estratégia impulsionadora de dinâmicas socioeconômicas mais ajustadas ao imperativo ambiental, aos objetivos de equidade e aos pressupostos de solidariedade intra e intergeracional, tendo a agroecologia como base desse novo paradigma de desenvolvimento.

As temáticas das atividades desenvolvidas, durante o projeto, possuem interface com a agroecologia à medida que estão alinhadas a suas dimensões ecológica, social, econômica, cultural, política e ética. Ressalta-se que a agroecologia pode ser entendida como um caminho direcionado ao desenvolvimento rural sustentável e consiste na busca de local para, a partir daí, recriar a heterogeneidade do mundo rural, por meio de formas de ação social coletiva, pautadas pelo protagonismo dos atores locais no processo de desenvolvimento (GUSMÁN, 2005). Nesse sentido, este projeto procurou explorar alternativas que propiciassem uma participação ativa, bem como permitiu a sua aproximação com os agentes nele envolvidos, visando estabelecer um processo educativo de comunicação.

Todos os espaços estimularam maior afinidade entre os participantes (amizades, trocas, parcerias, mutirões, entre outras), participantes e a sociedade civil organizada (como o movimento "Todos pela água") e, também, potencializaram maior proximidade dos participantes junto ao poder público (levando demandas à prefeitura e participando em espaços públicos como reuniões da câmara dos vereadores do município).

\section{Considerações finais}

Esta experiência foi marcada pelo diálogo e troca de saberes, pois construir e realizar dez reuniões e doze atividades com a comunidade constituiu-se resultado de um esforço coletivo entre a universidade e a sociedade. Essa interação promoveu, além disso, o enriquecimento da experiência docente e discente em termos teóricos, metodológicos e pessoais. O uso de metodologias sob uma concepção participativa propiciou a criação de espaços dialogicamente interativos e discursivamente mediados, conforme assinalado por Coelho (2005), propiciando estabelecer uma relação de reciprocidade e de compromisso entre as partes. Foram valorizadas as demandas e o conhecimento local, a fim de superar a ideia de que a Universidade possuía um saber acabado que seria oferecido à sociedade.

O projeto estimulou reflexões e práticas sobre o desenvolvimento rural sustentável e agroecologia que pudessem fortalecer a construção de uma sociedade mais democrática e sustentável. Muitos ainda são os desafios, tanto no que se refere à interação dialógica e à participação, quanto à mudança de concepção de desenvolvimento com ações práticas. Essa mudança, a transição para um desenvolvimento de uma sociedade mais sustentável, requer que as pessoas e as instituições reflitam sobre seus valores, suas escolhas, possíveis consequências e o tipo de relações que pretendem estabelecer.

O desenvolvimento rural sustentável foi pensado neste projeto, a partir da comunicação entre as pessoas, pessoas e natureza e da análise das prioridades e disponibilidade dos participantes. Nesse sentido, é essencial que haja iniciativas de interação da universidade com a sociedade que visem consolidar a agroecologia e o desenvolvimento rural sustentável, por meio da criação de espaços de diálogo, valorizando os saberes e as demandas da comunidade.

\section{Agradecimentos}

Agradecemos à Universidade Federal de Lavras, à Sociedade Brasileira de Eubiose (SBE), Departamento de São Thomé das Letras - MG (SBE-STL) e a todos os participantes deste projeto de extensão, sem os quais este trabalho não teria sentido.

\section{Referências}

ALTIERI, M. A. Agroecologia: bases científicas para uma agricultura sustentável. Guaíba: Agropecuária; AS-PTA, 2002. 592 p.

CAPORAL, F. R.; COSTABEBER, J. A. (Org.). Agroecologia e Extensão Rural Sustentável: Contribuições para a promoção do desenvolvimento rural sustentável. Brasília: MDA/SAF/DATER/IICA, v.1, 2004. 166 p. 
CAPORAL, F. R.; RAMOS, L.F.; CAPORAL, D. S., COSTABEBER, J. A.; PAULUS, G. (Org.). Extensão Rural e Agroecologia: temas sobre um novo desenvolvimento rural sustentável. 1.ed. Brasília: MDA/SAF, v.1, 2009. 408 p.

CASADO, G. G.; MOLINA, M. G. de; GUZMÁN, E. S. (coord.). Introducción a la Agroecología como desarrollo rural sostenible. Madrid: Ediciones Mundi-Prensa, 2000.

COELHO, F. M. G. A arte das orientações técnicas no campo: concepções e métodos. Viçosa: UFV, 2005. $139 \mathrm{p}$.

COSTABEBER, J. A.; CAPORAL, F. R. Possibilidades e alternativas do desenvolvimento rural sustentável. In: VELA, H. (Org.). Agricultura familiar e desenvolvimento rural sustentável no Mercosul. Santa Maria: Editora da UFSM/Pallotti, 2003. p.157-194.

FORPROEX - FÓRUM DE PRÓ-REITORES DE EXTENSÃO DAS UNIVERSIDADES PÚBLICAS BRASILEIRAS. Política Nacional de Extensão Universitária. Manaus: FORPROEX, 2012.

GLIESSMAN, S. R. Agroecologia: processos ecológicos em agricultura sustentável. Porto Alegre: Editora da UFRGS, 2000. 654 p.

GUZMÁN, E. S. Agroecologia e Desenvolvimento Rural Sustentável. In: AQUINO, A. M.; ASSIS, R. L. (Ed.). Agroecologia: Princípios e Técnicas para uma Agricultura Orgânica Sustentável. Brasília: Embrapa Informação Tecnológica, 2005. p. 101-132.

MOREIRA, R. M. CARMO, M. S. do. Agroecologia na construção do desenvolvimento rural sustentável. Agriculturas em São Paulo. São Paulo, v. 51, n. 2, p. 37-56, jul./dez. 2004.

VERDEJO, M. E. Diagnóstico rural participativo: guia prático DRP. Brasília, DF: MDA/Secretaria da Agricultura Familiar, 2006. 62 p.

Data de submissão: 30/3/2019. Data de aceite: 25/4/2019. 